$5-6$

\title{
Globalization of spine care: how are we doing and what are we doing?
}

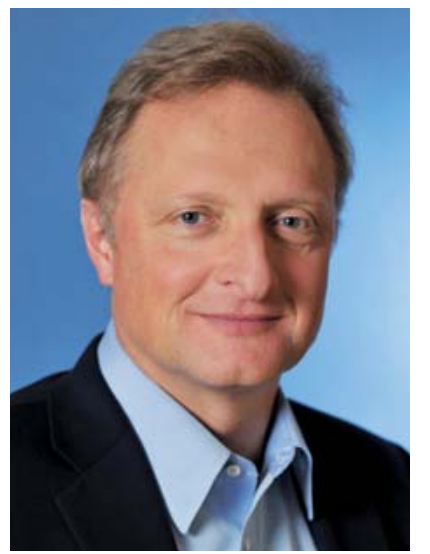

Jens Chapman

Table 1 Global membership AOSpine.

\begin{tabular}{|c|c|}
\hline Region & Jan 31, 2011 \\
\hline Asia Pacific & 2044 \\
\hline Europe & 1687 \\
\hline Latin America & 1195 \\
\hline $\begin{array}{l}\text { Middle East/ } \\
\text { North Africa }\end{array}$ & 390 \\
\hline North America & 1038 \\
\hline Global & 6354 \\
\hline
\end{tabular}

EBSJ has been in existence a bit more than 2 years now and has benefited from a steadily increasing stream of quality submission thanks to you, our readers, despite still not being 'visible' in some influential medical search engines, such as PubMed, notwithstanding our official acceptance there last year.

Let me address your pressing first question right away: both, US government officials in charge of PubMed, and our publisher Thieme Verlag, have assured me repeatedly that all of our EBSJ files are being actively (albeit slowly) downloaded as we are speaking and will be available online before years-end inclusive of all previously published articles to date. Delays apparently were caused by a combination of 'technical difficulties' and shortage in US government staffing. On behalf of the editorial staff and AOSpine International, I wish to apologize to all of those who are looking for our very noteworthy publications online and had a hard time finding them so far-your patience hopefully will be rewarded soon.

\section{EBSJ and its global readership}

In this editorial, I would like to point out the impressive interdisciplinary global wingspan of AOSpine with its more than 6000 members worldwide. As can be seen in Table 1, we have made impressive gains on our path of attracting dues-paying members worldwide to our core values of (1) unbiased knowledge creation, (2) quality education, and (3) forming a truly interdisciplinary global fellowship of like-minded ethically motivated spine practitioners searching for better care for our spine patients tomorrow.

EBSJ is proud to be part of this important mission and has made great strides in becoming an internationally relevant entity. As can be seen in Table $\mathbf{2}$, after 2 years of EBSJ existence, the diversity in countries of origin of scientific articles has expanded impressively. We hope that the current predominance of United States-derived articles will soon give way to the riches of insight available from a global audience reading and participating in EBSJ.

It is the global nature of our constituency that allows us to gain important new insights, which will shape the spine care of the future. To show the potential dilemmas facing global spine care, I direct your attention to an interesting case report in this edition of EBSJ by Michael P Silverstein and colleagues who report on a complex spine condition they encountered while serving on a medical relief mission in Uganda. Please let us know your thoughts on this case in form of a commentary or by responding to an upcoming survey.

\section{Important new insights in spine care: freely available through AOSpine}

In an effort to reach as many spine surgeons as possible worldwide beyond our own peer-reviewed publications with key scientific insights gained from its research, AOSpine has also taken the unprecedented step of purchasing publication rights to a potential breakthrough study from a major scientific publication-in this case the Journal of Neurosurgery: Spine. The results of the largest to-date-comparison study of its kind on timing of intervention for acute cervical spinal cord injury has produced the type of insights which may influence our surgical care delivery decisively-where possible-in favor of early intervention. 


\begin{tabular}{ll}
\hline $\begin{array}{l}\text { Table } 2 \text { EBSJ articles-countries } \\
\text { of origin }\end{array}$ & 1 \\
\hline Argentina & 2 \\
\hline Australia & 1 \\
\hline Brazil & 2 \\
\hline Canada & 1 \\
\hline China & 2 \\
\hline India & 5 \\
\hline Israel & 1 \\
\hline Kingdom of Jordan & 1 \\
\hline Mexico & 1 \\
\hline Netherlands & 1 \\
\hline New Zealand & 1 \\
\hline Slovenia & 1 \\
\hline South Africa & 1 \\
\hline Spain & 2 \\
\hline Sweden & 1 \\
\hline Switzerland & 20 \\
\hline Taiwan & 1 \\
\hline United kingdom & \\
\hline United States of America & \\
\hline
\end{tabular}

The study titled "Early versus Delayed Decompression for Traumatic Cervical Spinal Cord Injury: Results of the Surgical Timing in Acute Spinal Cord Injury Study (STASCIS)" by Michael G Fehlings, Alexander Vaccaro, Jefferson R Wilson, Anoushka Singh, David W Cadotte, James S Harrop, Bizhan Aarabi, Christopher Shaffrey, Marcel Dvorak, Charles Fisher, Paul Arnold, Eric M Massicotte, Stephen Lewis, and Raja Rampersaud has addressed one of the most pressing questions in spine trauma care: when to intervene?

On behalf of AOSpine it is our pleasure to make this likely game-changing article on spinal cord injury care globally available for free access and download under the following URL: http://tiny.cc/czhfbw

\section{A new frontier in Global spine publications: 'GSJ'}

Due to the growing demands of a global spine surgeon population we are about to further expand our scientific publication offerings to the AOSpine community worldwide with an important addition to our publication spectrum: It is my distinct pleasure to introduce the Global Spine Journal-'GSJ' with its Editor-in-chief Jeff Wang, MD, to our AOSpine International community. This new publication will alternate its distribution schedule with EBSJ and invite submissions in the domains of basic research, surgical techniques, case series, historical and literature reviews and, of course, interesting case reports. EBSJ will continue with its core publications of comparative effectiveness studies, outcomes and patient safety investigations, public health and epidemiological studies, and its popular formal 'Systematic Reviews' (produced in conjunction with trained epidemiologists), as well as its well-received 'Case controversies' and 'Science in spine' features.

For anyone interested in submitting but not sure where to do so, there is no need to worry-either submissions portal will work and our Editorial staff will direct your study to the most suitable Journal within our AOSpine scientific publications family.

We are glad to have you as our readers and contributors and hope that you will participate in the most exciting spine educational and investigational movement around: AOSpine!

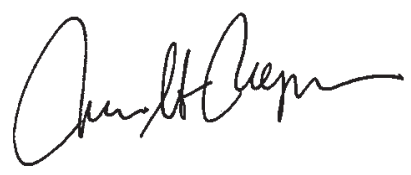

Jens Chapman

Editor-in-chief 